\title{
Variabilidade fenotípica de Rumohra adiantiformis (G. Forst) Ching (Dryopteridaceae)
}

\author{
Maria Regina Torres Boeger ${ }^{1,2}$, Leticia Estela Cavichiolo ${ }^{1}$, Maria Whilhelmina Pil ${ }^{1}$ e Paulo Henrique Labiak ${ }^{1}$
}

Recebido: 07.12.2006; aceito: 21.11.2007

\begin{abstract}
Phenotypic variability of Rumohra adiantiformis (G. Forst) Ching (Dryopteridaceae)). Rumohra adiantiformis is a widely distributed species of Pteridophyte, known as black-fern and often used for floral bouquets. The plants have different leaf shapes and sizes according to the environment they occur. This paper describes the phenotypic variability of individuals of $R$. adiantiformis with distinct habits and environments, using morphological traits as indicators of plasticity. Leaves collected in three different types of vegetation were measured. The main values of total leaf length, leaf area, stomatal density, and thickness of mesophyll were significantly different among the three environments. The data suggests that $R$. adiantiformis shows phenotypic variability for most of the traits analyzed, the individuals of sunny terrestrial habitats were the most morphologically distinct. This result is probably associated with more stressing conditions of this environment, such as water deficit and higher light intensity.
\end{abstract}

Key words: leaf anatomy, leaf morphology, plasticity

RESUMO - (Variabilidade fenotípica de Rumohra adiantiformis (G. Forst) Ching (Dryopteridaceae)). Rumohra adiantiformis é uma pteridófita amplamente distribuída em regiões tropicais, conhecida como samambaia-preta e utilizada em arranjos florais. Suas frondes possuem formas e tamanhos variados, de acordo com o ambiente onde ocorrem. Este trabalho teve como objetivo avaliar a variabilidade fenotípica dos indivíduos desta espécie com hábitos e ambientes de ocorrência distintos, utilizando características morfológicas como indicadores de plasticidade. Frondes, de três diferentes formações vegetacionais, foram coletadas para a medição dos parâmetros morfológicos. Os valores médios de comprimento total da fronde, área foliar, densidade estomática e espessuras do mesofilo foram significativamente diferentes entre os três ambientes. Os dados sugerem que $R$. adiantiformis apresentou variabilidade fenotípica para a maioria das características analisadas, sendo que os indivíduos de hábito terrícola de sol foram os que mais diferiram morfologicamente em função das condições ambientais mais estressantes como maior deficit hídrico e a maior intensidade luminosa que estas plantas estão expostas. Palavras-chave: anatomia foliar, morfologia foliar, plasticidade

\section{Introdução}

A habilidade de uma determinada espécie de ajustar a sua morfologia e/ou fisiologia em decorrência de sua interação com o ambiente é chamada de plasticidade fenotípica. Estes ajustes permitem um melhor uso dos recursos disponíveis no ambiente, mesmo em condições estressantes (Sultan 2000, Cardoso \& Lomônaco 2003). Entre todos os órgãos vegetais, a folha é o órgão mais plástico da planta, aclimatando-se rapidamente em função das variações dos fatores ambientais (Gratani et al. 2006). Vários estudos têm demonstrado que as folhas de angiospermas apresentam alto grau de plasticidade entre populações ou, até mesmo, dentro de um único indivíduo (Bruschi et al. 2003). No entanto, estudos com pteridófitas sob este enfoque são escassos (Saldaña et al. 2005).

Rumohra adiantiformis (G. Forst) Ching (Dryopteridaceae) se destaca entre as pteridófitas por sua importância econômica, uma vez que suas folhas são comercializadas para utilização em arranjos florais. As folhas comercializadas são obtidas, na maioria das vezes, através da extração direta do seu ambiente natural (Ribas \& Miguel 2004). O extrativismo desta espécie, popularmente denominada de samambaiapreta, tem sido bastante intenso na Floresta Ombrófila Densa da Região Sul e Sudeste do Brasil. Somente

1. Universidade Federal do Paraná, Departamento de Botânica, Caixa Postal 19031, 81531-980 Curitiba, PR, Brasil

2. Autor para correspondência: rboeger@ufpr.br 
na região da Encosta Atlântica do Rio Grande do Sul, a estimativa é de que cerca de três mil famílias tenham sua renda a partir da extração de folhas de samambaiapreta (Ribas \& Miguel 2004).

Rumohra adiantiformis possui uma ampla distribuição geográfica, ocorrendo em quase todos os países do Neotrópico, África, Madagascar, Nova Zelândia e Austrália, além de algumas áreas de clima subtropical. Esta espécie é encontrada em uma gama bastante variada de ambientes, com hábitos também bastante distintos, sendo em algumas áreas encontrada mais comumente como epífita ou rupícola e, em outras, ocupando predominantemente o ambiente terrestre, desde o nível do mar até 1.500 m s.n.m. (Labiak \& Prado 1998).

Devido a estas características ecológicas e biogeográficas, as diferentes populações apresentam respostas fenotípicas próprias para cada ambiente de ocorrência, o que levou à descrição de várias espécies que, atualmente, são tratadas como sinônimos de Rumohra adiantiformis (e.g. Aspidium capense Sw., Polypodium coriaceum Sw., Polypodium politum Poir. e Rumohra aspidioides Raddi).

Assim, esse trabalho teve como objetivo avaliar a variabilidade fenotípica dos indivíduos desta espécie procedentes de três formações vegetacionais distintas, utilizando características morfológicas e anatômicas como indicadores de plasticidade.

\section{Material e métodos}

Descrição das áreas de estudo - Os indivíduos de $R$. adiantiformis foram coletados em três regiões distintas: o Parque dos Mananciais da Serra (PMS), a planície litorânea de Guaratuba (PLG) e o Parque Estadual do Palmito (PEP). O Parque dos Mananciais da Serra é propriedade do Governo Estadual, sob jurisdição do Departamento de Água e Esgotos, hoje SANEPAR. Localiza-se na Serra do Mar, no município de Piraquara, Região Metropolitana de Curitiba, PR

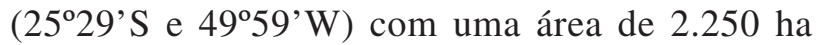
(Reginato \& Goldenberg 2007) e altitude média de 1.100 m s.n.m., com vegetação predominante de Floresta Ombrófila Densa Montana e Alto-montana (Reginato \& Goldenberg 2007). Seu relevo é constituído de um sistema montanhoso paralelo à linha da costa, com clima do tipo $\mathrm{Cfb}$, de acordo com a classificação de Köeppen (IAPAR 1994). A temperatura média anual é de $16,6^{\circ} \mathrm{C}$, sendo a média do mês mais frio de $13,3{ }^{\circ} \mathrm{C}$ e a média do mês mais quente $20,6^{\circ} \mathrm{C}$. A precipitação oscila entre $1.250 \mathrm{e}$
$2.500 \mathrm{~mm}$, sendo que os meses de inverno apresentam menor precipitação do que os meses de verão. A umidade relativa é entre 80 e $85 \%$ (Reginato \& Goldenberg 2007). Nesta área os indivídiuos de $R$. adiantiformis ocorrem como epífitas no estrato médio da floresta, em ambiente sombreado. A intensidade luminosa foi estimada em $6,8 \%$.

A Planície Litorânea de Guaratuba (PLG) está localizada no município de Guaratuba, PR (2556'64"S e 48 $35^{\prime} 23^{\prime \prime} W$ ). Nesta região predominam os solos de areia quartzosa, com drenagem bastante eficiente, tendo as restingas como cobertura vegetal predominante, com forte influência marinha. Segundo Köeppen (IAPAR 1994), o clima da região é classificado como subtropical úmido (Cfa), sem estação seca, com temperatura média em todos os meses igual ou superior a $18{ }^{\circ} \mathrm{C}$. O mês mais seco apresenta precipitação média acima de $60 \mathrm{~mm}$ e isento de geadas. A elevação da maré é de $6 \mathrm{~m}$ e a linha da praia (maré baixa sizigia) é de 26 metros. Nesta área os indivíduos de $R$. adiantiformis apresentam-se como terrícolas, totalmente expostos ao sol. A intensidade luminosa foi estimada em $100 \%$.

O Parque Estadual do Palmito (PEP) também se localiza na planície litorânea do Paraná, no município de Paranaguá $\left(25^{\circ} 35^{\prime} \mathrm{S}\right.$ e $\left.48^{\circ} 32^{\prime} \mathrm{W}\right)$, com uma área de 1.780 ha. O solo nessa região é classificado como espodossolo com textura arenosa, sendo a vegetação predominante classificada como Floresta Ombrófila Densa das Terras Baixas (Boeger et al. 2005). De acordo com a classificação de Köeppen (IAPAR 1994), o clima é caracterizado como subtropical, úmido (Cfa), sem estação seca e isenta de geadas. A temperatura média anual é de $21,9{ }^{\circ} \mathrm{C}$, sendo que a temperatura média do mês mais quente é acima de $22{ }^{\circ} \mathrm{C}$ e a do mês mais frio é de $18^{\circ} \mathrm{C}$ (Boeger et al. 2005). Nesse local os indivíduos de $R$. adiantiformis também têm hábito terrícola, fazendo parte do subosque, em locais sombreados. A intensidade luminosa foi estimada em $6 \%$ da intensidade luminosa total.

Amostragem - Os materiais testemunho foram coletados para cada área amostrada e estão depositados no Herbário UPCB, da Universidade Federal do Paraná, sob os seguintes números de registro: (PMS) 36027; (PEP) 53905 e (PLG) 53906.

Foram coletadas 18 frondes por formação vegetacional, que tiveram seus comprimentos mensurados com trena, imediatamente após a coleta. Posteriormente, as frontes foram prensadas entre papel 
jornal e desidratadas em estufa a $50^{\circ} \mathrm{C}$ até atingirem peso constante para a mensuração de suas massas secas em balança analítica de precisão Celtac $(0,0001 \mathrm{~g})$. A área foliar foi estimada através da imagem das frondes digitalizada em scanner de mesa acoplado ao computador, com o programa SIGMASCAN-PRO (versão 4.0, SPSS Inc., Chicago, IL, USA, 1995). A classificação da área da fronde seguiu aquela de Raunkiaer, modificada por Webb (1959), a qual considera as seguintes categorias: nanofilia: 0,25-2,25 $\mathrm{cm}^{2}$; microfilia: 2,25-20,25 $\mathrm{cm}^{2}$; notofilia: 20,25-45 cm²; mesofilia: 45-182,25 $\mathrm{cm}^{2}$; macrofilia: $82,25-1.640,25 \mathrm{~cm}^{2}$; megafilia $>1.640,25 \mathrm{~cm}^{2}$. A densidade foliar foi calculada utilizando-se a seguinte relação: (MS/AF).(1/ET), onde MS = massa seca $(\mathrm{mg}), \mathrm{AF}=$ área foliar $\left(\mathrm{mm}^{2}\right)$ e ET = espessura total (mm) (Witkowski \& Lamont 1991).

A densidade estomática foi estimada utilizandose a modelagem da epiderme do terço médio das frondes com esmalte sintético incolor. Os estômatos foram contados em dois campos de $1 \mathrm{~mm}^{2}$ por indivíduo, em microscópio óptico Olympus CBB provido de câmara clara. A contagem foi realizada apenas na epiderme da face abaxial, por se tratar de uma fronde hipoestomática.

Para análise anatômica foliar, secções da região mediana de folíolos foram fixadas em FAA em etanol $70 \%$ e preservadas em etanol $70 \%$. As observações anatômicas foram feitas através da confecção de lâminas permanentes, seguindo as técnicas usuais para emblocamento em glicolmetacrilato (Feder \& O'Brien 1968) e através de lâminas semipermanentes, com secções histológicas feitas com lâmina de barbear, clarificadas com hipoclorito de sódio a $10 \%$ e coradas com azul de toluidina a $0,5 \%$, em solução aquosa.

Para a medição das espessuras de tecidos foram utilizados cortes transversais da região mediana dos folíolos, obtidos com auxílio de lâmina de barbear. Foram medidas as espessuras da epiderme das faces adaxial e abaxial, espessura total da lâmina e do mesofilo. As medições foram realizadas em microscópio óptico Olympus CBB, com auxílio de ocular micrometrada. A intensidade luminosa foi estimada com luxímetro digital Chauvin Arnoux, modelo CA 810 (Paris, França).

As médias e os respectivos desvios-padrão de todas as variáveis quantitativas foram calculadas. Uma análise de variância de uma via (ANOVA) foi realizada para todas as variáveis. A normalidade dos resíduos foi testada e as médias foram comparadas através do
Teste de Comparação Múltipla de Fisher no programa STATISTICA (versão 6.0, StatSoft, Inc., Tulsa, OK, USA 1998), com nível de 5\% de probabilidade. Com este mesmo programa, também foi calculado o coeficiente de correlação de Pearson, tendo sido considerada correlação alta quando $r \leq 0,6$ e $r \geq 0,6$. A análise dos componentes principais (PCA) foi utilizada para determinar a maior variância entre as variáveis quantitativas, através do programa Past, versão 1,34 (Hammer et al. 2001).

\section{Resultados}

Os valores médios do comprimento total da fronde, área foliar, densidade estomática e espessuras total e do mesofilo foram significativamente diferentes entre os três ambientes, mas não seguiram o mesmo padrão. Os valores médios do comprimento total das frondes e da área foliar foram maiores nos indivíduos do PEP. Entretanto, os maiores valores médios da espessura do mesofilo e espessura total ocorreram nas frondes dos indivíduos do PLG. Este resultado indica uma relação inversa entre as espessuras (mesofilo e total) com o comprimento total da fronde e a área foliar (tabela 1). Os menores valores para estas duas últimas variáveis ocorreram nos indivíduos do PLG e os maiores valores de espessura do mesofilo nas plantas do PEP (tabela 1). Apesar da diferença significativa entre as áreas foliares, o tamanho foliar, do tipo macrófila, foi o mesmo para as três populações estudadas.

Os menores valores de massa seca ocorreram nas frondes das plantas da PLG, que difereriram estatisticamente das frondes das demais plantas. As frondes de PEP e PMS não diferiram estatisticamente entre si (tabela 1).

Os valores médios de densidade das frondes dos indivíduos do PEP e da PLG não diferiram significantemente das plantas do PMS. Os valores médios da espessura da epiderme adaxial das frondes dos indivíduos do PEP e do PMS foram significativamente diferentes, embora não tenham diferido significativamente das frondes de PLG (tabela 1). As frondes variaram também entre o grau de inclinação em relação ao solo, sendo que as frondes do PLG são mais orientadas verticalmente do que as frondes do PEP e PMS.

A análise de PCA (figura 1) mostrou que os dois primeiros componentes (PC1 e PC2) explicam 70,9\% da variância total das características analisadas. PC1 
Tabela 1. Valores médios ( \pm desvio-padrão) das características morfológicas e anatômicas de Rumohra adiantiformis de hábito terrícola de sombra (PEP), epifítico (PMS) e terrícola de sol (PLG). Letras diferentes para a mesma variável indicam valores estatisticamente significantes (Fisher, $\mathrm{p}<0,05, \mathrm{n}=15$ ).

\begin{tabular}{lccc}
\hline Características & PEP & PMS & PLG \\
\hline Comprimento da fronde $(\mathrm{cm})$ & $116,5( \pm 12,8) \mathrm{a}$ & $96,9( \pm 19,3) \mathrm{b}$ & $61,0( \pm 7,8) \mathrm{c}$ \\
Área foliar $\left(\mathrm{cm}^{2}\right)$ & $708,8( \pm 176,8) \mathrm{a}$ & $594,6( \pm 163,6) \mathrm{b}$ & $322,5( \pm 102,1) \mathrm{c}$ \\
Tamanho foliar & macrófila & macrófila & macrofila \\
Massa seca $(\mathrm{g})$ & $7,3( \pm 2,3) \mathrm{a}$ & $6,8( \pm 2,0) \mathrm{a}$ & $4,4( \pm 1,7) \mathrm{b}$ \\
Densidade da fronde $\left({\left.\mathrm{mg} \cdot \mathrm{mm}^{-3}\right)}^{-3}\right)$ & $0,58( \pm 0,1) \mathrm{a}$ & $0,51( \pm 0,1) \mathrm{ab}$ & $0,46( \pm 0,2) \mathrm{b}$ \\
Densidade estomática $\left(\mathrm{n} \cdot \mathrm{mm}^{-2}\right)$ & $184,8( \pm 37,1) \mathrm{b}$ & $134,3( \pm 18,1) \mathrm{c}$ & $219,0( \pm 34,9) \mathrm{a}$ \\
Espessura da face adaxial da epiderme $(\mu \mathrm{m})$ & $15,1( \pm 1,7) \mathrm{a}$ & $13,1( \pm 2,0) \mathrm{b}$ & $14,1( \pm 1,9) \mathrm{ab}$ \\
Espessura do mesofilo $(\mu \mathrm{m})$ & $132,0( \pm 10,1) \mathrm{c}$ & $189,6( \pm 36,3) \mathrm{b}$ & $268,6( \pm 54,0) \mathrm{a}$ \\
Espessura total $(\mu \mathrm{m})$ & $177,1( \pm 8,6) \mathrm{c}$ & $233,1( \pm 35,2) \mathrm{b}$ & $314,1( \pm 55,1) \mathrm{a}$ \\
Espessura da camada subepidérmica $(\mu \mathrm{m})$ & $17,4( \pm 1,9) \mathrm{a}$ & $18,11( \pm 5,8) \mathrm{a}$ & $17,5( \pm 2,5) \mathrm{a}$ \\
\hline
\end{tabular}

explicou $54,2 \%$ da variância e é representado principalmente pela área foliar. PC2 explicou 16,7\% da variância e é representado principalmente pela densidade estomática (tabela 2). No PC1, a área foliar apresenta uma relação negativa com a densidade estomática e a espessura total da lâmina. No PC2, a densidade estomática é negativamente relacionada com o comprimento da fronde. Essa análise indicou, também, que os indivíduos do PLG são morfologicamente mais distintos dos que os indivíduos do PEP e dos indivíduos do PMS, para o conjunto de características analisadas.

Anatomicamente, os segmentos da fronde de $R$. adiantiformis apresentam epiderme uniestrati-

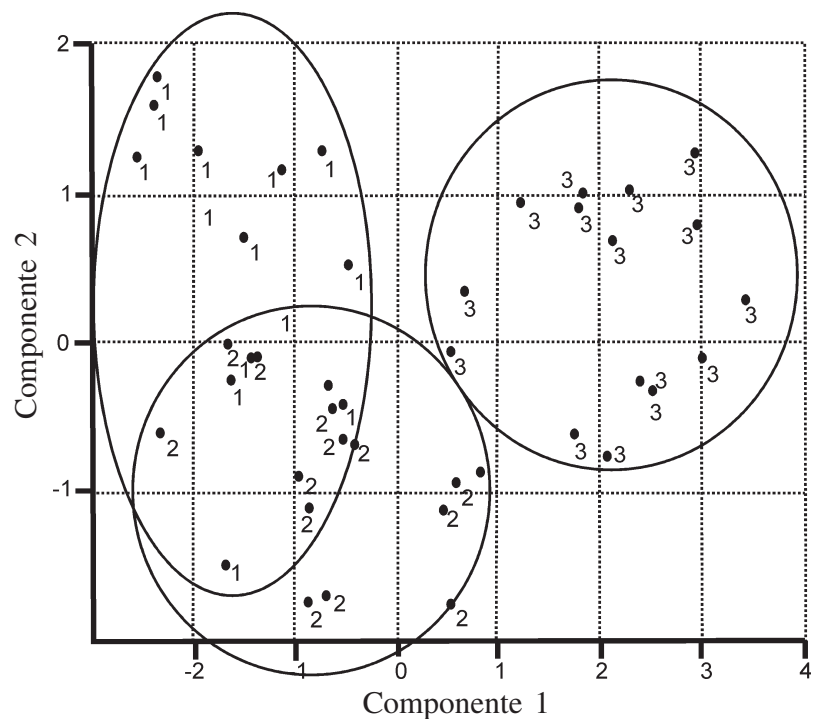

Figura 1. Análise de PCA das características morfológicas dos indivíduos de Rumohra adiantiformis nas formações vegetacionais de hábito terrícola de sombra $(\mathrm{PEP}=1)$, epifítico $(\mathrm{PMS}=2)$ e terrícola de sol $(\mathrm{PLG}=3)$.
Tabela 2. Componentes principais da matriz de correlação entre as medidas das frondes de Rumohra adiantiformis $(\mathrm{n}=15)$.

\begin{tabular}{lcc}
\hline \multirow{2}{*}{ Características } & \multirow{2}{*}{ Componente principal } \\
\cline { 2 - 3 } & \multicolumn{1}{c}{1} & 2 \\
\hline Área foliar & $-6,62$ & 0,35 \\
Massa seca & $-5,64$ & 1,33 \\
Comprimento da fronde & $-5,20$ & $-2,14$ \\
Densidade estomática & 1,98 & 4,25 \\
Espessura total da lâmina & 4,90 & 3,83 \\
Espessura da camada subepidérmica & 0,33 & 0,21 \\
Variância explicada pelos componentes & 2,94 & 0,90 \\
Percentagem do total da variância & 54,22 & 16,70 \\
$\quad$ explicada (\%) & & \\
\hline
\end{tabular}

ficada, que em vista frontal, possui a face adaxial formada por células tabulares com paredes anticlinais retilíneas e espessadas (figura 2). Na face abaxial, as células possuem paredes anticlinais sinuosas e espessadas (figura 3). Nessa face se encontram os estômatos anomocíticos (figura 3 ) e os soros.

$\mathrm{Na}$ face adaxial, em secção transversal, as células epidérmicas variam de alongadas a isodiamétricas, com parede espessada, sendo a parede periclinal externa cutinizada (figuras 4-7).

A parede cutinizada da face adaxial da fronde é mais espessa do que na face abaxial, nas três formações vegetacionais. Internamente à epiderme, na face adaxial, observa-se de uma a duas camadas de células subepidérmicas de forma e tamanho variados, com parede espessada, sendo a camada mais interna descontínua (figuras 4-6). Algumas células apresentam conteúdo escuro, provavelmente, devido a presença de compostos fenólicos. 

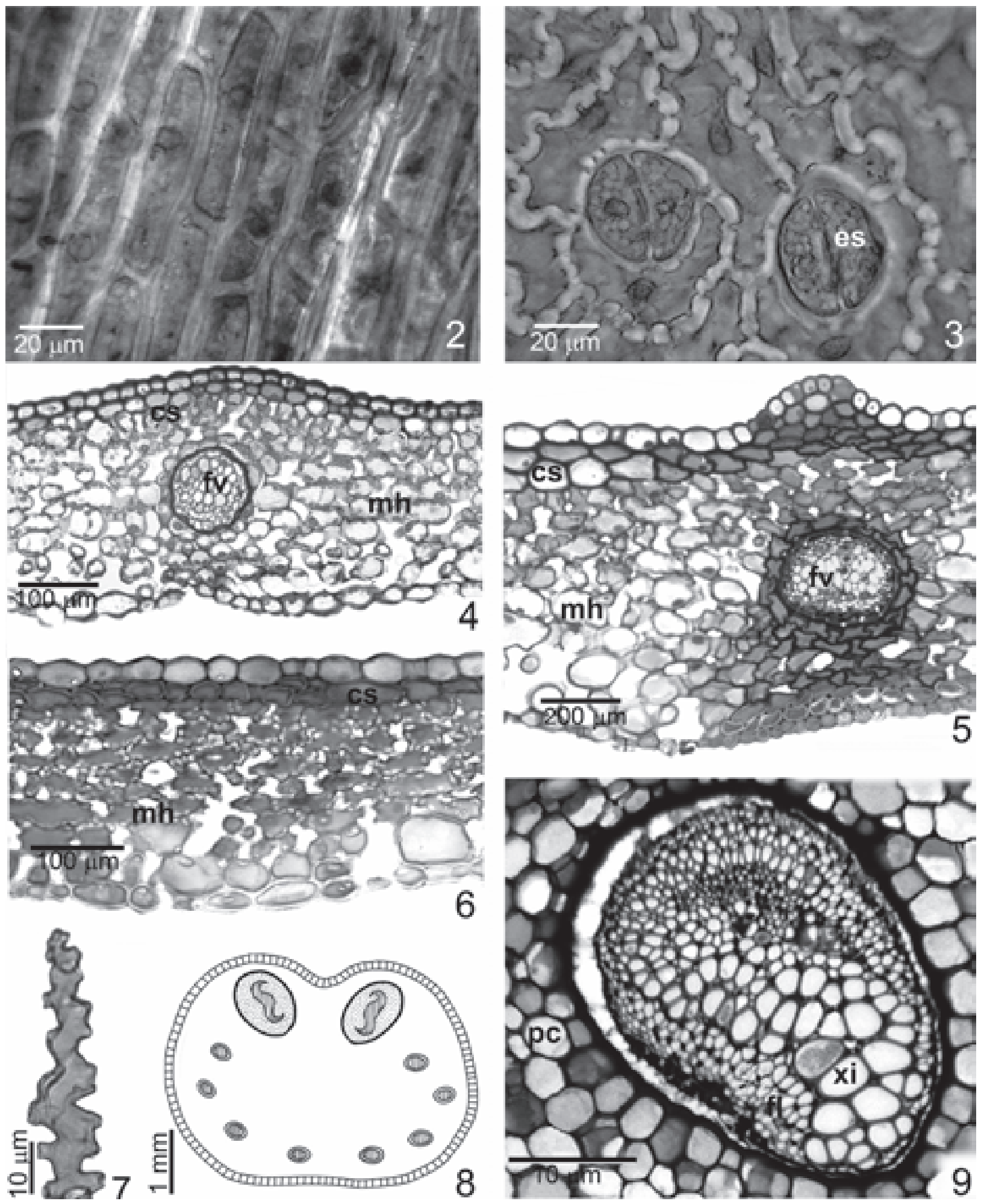

Figuras 2-9. Rumohra adiantiformis. 2. Vista frontal da face adaxial da epiderme. 3. Vista frontal da face abaxial da epiderme, evidenciando estômato (es). 4. Secção transversal da lâmina foliar de indivíduos de PEP. 5. Secção transversal da lâmina foliar de indivíduos de PMS. 6. Secção transversal da lâmina foliar de indivíduos de PLG. 7. Detalhe da célula braciforme. 8. Desenho esquemático do pecíolo, em secção transversal. Linha dupla com barras verticais representa a epiderme, traço vertical representa o xilema e o pontilhado representa o floema. 9. Detalhe do meristelo de maior porte do pecíolo, em secção transversal. cs = camada subepidérmica; fv = feixe vascular; $\mathrm{mh}=$ mesofilo homogêneo; $\mathrm{xi}=$ xilema; $\mathrm{fl}=$ floema . 
O mesofilo da fronde de $R$. adiantiformis é homogêneo, constituído de células parenquimáticas braciformes (figuras 4-7), com sete a dez camadas. As células deste parênquima apresentam formato e tamanho bastante variado. Na região da nervura mediana, o feixe vascular é do tipo colateral, sendo delimitado por endoderme uniestratificada e periciclo que algumas vezes pode ser biestratificado. Não foram observadas diferenças quanto à organização interna entre os folíolos das frondes das três formações vegetacionais estudadas, apenas variações no número de estratos do parênquima homogêneo.

O pecíolo de $R$. adiantiformis, na sua região mediana, é revestido por uma epiderme uniestratificada, cujas células são tabulares e com parede celular espessa. Em vista transversal, as células são pequenas, isodiamétricas, com parede uniforme e espessa.

Cada feixe vascular do pecíolo é envolvido por uma bainha cujas células apresentam paredes com espessamento de aspecto radiado. Em secção transversal, os meristelos estão dispostos em forma de arco (figura 8), do tipo Aspidium. Nas porções apicais do arco, os meristelos apresentam o xilema na forma de "cavalo marinho" e são de maior porte, onde as extremidades de protoxilema possuem terminações recurvadas (figura 9). Nestes meristelos, o floema contorna o xilema. Os meristelos posicionados mais internamente no arco são elípticos ou arredondados. Esses meristelos são formados por xilema central e floema bicolateal (tipo Marattia). As células do parênquima cortical também se apresentam espessadas e algumas com conteúdo escuro, provavelmente, também devido à presença de compostos fenólicos.

\section{Discussão}

Os resultados obtidos claramente indicam que a espécie em estudo apresentou variabilidade fenotípica, para a maioria das características analisadas, a qual tem sido reconhecida como uma habilidade que permite que as espécies respondam à heterogeneidade de ambientes, como uma estratégia para colonizar e se desenvolver em condições mais adversas (Sultan 2000). Entre as três populações de $R$. adiantiformis estudadas, os indivíduos de PLG foram os que mais diferiram morfologicamente em função das condições ambientais mais estressantes, como maior déficit hídrico, uma vez que o solo arenoso das dunas não retém muita água, e a maior intensidade luminosa que estas plantas estão expostas. Características como inclinação da fronde, espessura da lâmina, menor área foliar, menor comprimento da fronde e maior densidade estomática podem ser entendidas como estratégias para reduzir os efeitos deletérios da luz e déficit de água, em períodos mais quentes do ano (Fahn \& Cutler 1992).

O menor comprimento da fronde e, conseqüentemente, a menor área foliar são características tipicamente encontradas em plantas de ambientes ensolarados, xéricos, deficientes em nutrientes ou sob a ação de outro agente estressante, como por exemplo, ventos intensos (Puijalon \& Bornette 2004). Esses são mecanismos considerados preventivos contra a perda de água e superaquecimento (Parkhust \& Loucks 1972, Bongers \& Popma 1988). A menor área foliar diminui a superfície exposta à intensidade luminosa, minimizando as taxas de transpiração (Medri \& Lleras 1980). Associado a essa condição de luz, os solos arenosos, como os da PLG, encontram-se expostos ao déficit hídrico devido a menor capacidade de reter água. Essa característica induz as plantas que ali crescem a desenvolver mecanismos de retenção de água, como a redução da área foliar (Parkhust \& Loucks 1972). Outro fator que contribui para a diminuição da área foliar é a forma pinada das frondes. As eudicotiledôneas, que possuem folhas com a lâmina profundamente lobada ou folhas compostas, são comumente encontradas em ambientes áridos ou semi-áridos, uma vez que os recortes na lâmina reduzem a superfície foliar exposta (Givnish 1988).

A diferença significante da área foliar entre os três grupos de plantas não se reflete na densidade da fronde, cujos valores médios são diferentes estatisticamente apenas entre os indivíduos de PEP e PLG. Isto indica que a densidade é fortemente influenciada pelos valores médios das espessuras do mesofilo e total. Apesar da área foliar ser fortemente correlacionada com a massa seca $(r=0,86, p<0,05)$, os valores de massa seca dos indivíduos PEP e PMS são próximos e não estatisticamente diferentes. As frondes do PEP são $16 \%$ e 54,5\% maiores do que as frondes do PMS e PLG, respectivamente, enquanto que, em termos de massa seca esta diferença é em torno de 6,9 e $39,7 \%$ e, em termos de espessura, é de $24 \%$ e $116 \%$. Já as espessuras total e do mesofilo são inversamente correlacionadas com a área foliar $(r=-0,70 ; r=-0,69, p<0,05)$. Tais relações parecem ter suporte na pouca quantidade de tecido mecânico das frondes e no maior investimento de tecido 
fotossintético, representado pela maior espessura. Estes dados não corroboram com os encontrados para estudos com angiospermas, onde se observa um maior incremento de tecido mecânico à medida que as condições de luz e déficit hídrico aumentam (Marques et al. 2000, Roças et al. 2001).

A vantagem do mesofilo mais espesso, em folhas de menor área foliar, é a maior fixação de $\mathrm{CO}_{2}$ e menor perda de água através da respiração (Givnish 1988, Klich 2000). O ajuste morfológico das frondes, especialmente na relação área/espessura, permite a manutenção do balanço positivo de carbono nos diferentes ambientes em que ocupa e isto é a característica chave para a ocupação com sucesso em habitats diversos (Spencer \& Teeri 1994).

A maior espessura reflete também na textura das frondes, sendo os indivíduos da PLG os que apresentam frondes mais coriáceas. Esta textura é interpretada como o resultado das características anatômicas da lâmina, como a presença de epiderme com parede cutinizada espessa, presença de camada subepidérmica com células de paredes espessadas e das várias camadas que compõem a espessura do mesofilo (Turner 1994).

As frondes dos indivíduos da PLG são mais orientadas verticalmente, possivelmente, como consequiência da menor área foliar e maior espessura das frondes. A inclinação vertical das folhas também se relaciona com a redução do excesso de luz incidida na face adaxial, principalmente nas horas mais quentes do dia, além de permitir maior incidência de luz na superfície abaxial (DeLucia et al. 1991, Myers et al. 1997). No entanto, folhas com esta inclinação, geralmente, apresentam mesofilo isobilateral ou homogêneo, formado por parênquima paliçádico bem desenvolvido e/ou parênquima lacunoso compacto, além de apresentarem estômatos em ambas as faces (Poulson \& DeLucia 1993). Em R. adiantiformis, o mesofilo é homogêneo, composto por células braciformes que caracterizam um tecido com maior quantidade de espaços intercelulares e os estômatos ocorrem na face abaxial. Não foram observadas diferenças na organização do parênquima clorofiliano, apenas na espessura deste, que foi maior nas frondes de PLG. Segundo Ogura (1972), a organização do mesofilo em pteridófitas, varia de homogêneo, em lâminas finas, ou diferenciado em parênquima paliçádico e lacunoso, em mesofilos mais espessos. A ocorrência de células com expansões são comuns em alguns gêneros e o tecido recebe a denominação de tecido paliçádico braciforme (arm-palisade tissue), como em $R$. adiantiformis.

A camada subépidermica da face adaxial também não variou em espessura, assim como não foram observadas diferenças na espessura da cutícula, que é bem desenvolvida. Provavelmente, estas características (camada subepidérmica e cutícula espessa) ajam como uma barreira contra a dessecação, em condições mais quentes.

A presença de estômatos apenas na face abaxial também é considerada como um mecanismo preventivo às condições de luz intensa (Pyykkö 1979) e a maioria das espécies vegetais vasculares apresentam esta característica (Dickison 2000). Apesar da orientação vertical e maior espessura das frondes de PLG, não foram observados estômatos na face adaxial, como comumente ocorre em folhas verticais. Provavelmente, a ausência de estômatos na face adaxial seja devido a pouca espessura das frondes. O anfiestomatismo é comum em folhas espessas (> $500 \mu \mathrm{m})$, que impõe uma limitação na difusão interna do $\mathrm{CO}_{2}$, devido o maior percurso a ser percorrido pelos gases, dentro do mesofilo (Mott et al. 1992, Thompson et al. 1992).

Já os maiores valores médios de densidade estomática das plantas da PLG podem estar associados às condições mais xéricas. Em angiospermas, quanto maior a freqüência estomática por unidade de área, maior é a eficiência das trocas gasosas, uma vez que os estômatos podem permanecer abertos num período menor de tempo, quando as condições ambientais são mais favoráveis (Roças et al. 2001). Entretanto, em pteridófitas, sabe-se que o processo de fechamento dos estômatos é mais lento do que nas angiospermas, o que poderia limitar a efetividade das respostas estomáticas às variações locais (Woodhouse \& Nobel 1982, Robinson 1994).

A análise de PCA mostrou que, para o conjunto de características analisadas, as frondes dos indivíduos PEP e PMS são mais semelhantes morfologicamente entre si, apesar de diferenças significativas observadas entre estes dois grupos. As condições de luminosidade destes dois ambientes (PEP e PMS) são semelhantes e parecem explicar as semelhanças morfológicas entre algumas características das frondes. As condições hídricas, apesar de distintas entre essas formações vegetacionais, não parecem influenciar a morfologia de maneira significativa. As epífitas (PME) estão sujeitas a maiores oscilações hídricas do que as terrícolas de sombra (PEP) (Kluge et al. 1989), que 
estão sobre solo arenoso (espodossolo) coberto por serapilheira, onde ocorre uma melhor retenção de água (Boeger et al. 2005).

Segundo Kluge et al. (1989), as pteridófitas epifíticas são tolerantes à dessecação, apresentando características morfológicas para a economia de água, como cutícula espessa, redução da superfície e estômatos cobertos por tricomas. Entre os indivíduos epifíticos estudados, apenas a cutícula espessa foi evidenciada, juntamente com a presença de camada subepidérmica, porém estas características também foram encontradas nos outros indivíduos estudados.

Apesar das frondes do PMS serem menores que as frondes do PEP, elas ainda são cerca de $37 \%$ maiores do que as frondes de PLG, indicando que os ajustes morfológicos e, conseqüentemente, fisiológicos para a condição hídrica são diferenciados entre as três populações. Muitas pteridófitas epitíficas de florestas tropicais úmidas apresentam tecidos de reserva de água nas folhas e possuem metabolismo CAM (Kluge et al. 1989, Lüttge 1997). No entanto, a suculência não foi observada em frondes de $R$. adiantiformis.

A exemplo das angiospermas, a variabilidade fenotípica dessa espécie resulta da interação das condições diferenciadas principalmente de luz e disponibilidade hídrica, formando um gradiente de meso-xeromorfia entre as formações vegetacionais estudadas $(\mathrm{PEP}>\mathrm{PMS}>\mathrm{PLG})$, como indicado pelas características morfológicas da área foliar, espessura e densidade estomática. Rumohra adiantiformis parece ter a habilidade de usar eficientemente os recursos disponíveis, aumentando seu potencial de dispersão por diferentes formações vegetacionais com condições ambientais distintas, apresentando diferentes hábitos e morfologias (Saldaña et al. 2005).

\section{Literatura citada}

Boeger, M.R.T., Wisniewski, C. \& Reissmann, C.B. 2005. Nutrientes foliares de espécies arbóreas de três estádios sucessionais de floresta ombrófila densa no sul do Brasil. Acta Botanica Brasilica 19: 167-181.

Bongers, F. \& Popma, J. 1988. Is exposure-related variation in leaf characteristics of tropical rain forest species adaptive? In: M.J.A. Werger, P.J.M. van der Aart, H.J. During, J.T.A. Verhoeven (eds.). Plant Form and Vegetation Structure. SPB. Academic Publishing, The Hague. pp. 191-200

Bruschi, P., Grossoni, P. \& Bussoti, F. 2003. Within-and among-tree variation in leaf morphology of Quercus petraea (Matt.) Liebl. natural populations. Trees 17: 164-172.
Cardoso, G.L. \& Lomônaco, C. 2003. Variações fenotípicas e potencial plástico de Eugenia calycina Cambess. (Myrtaceae) em uma área de transição cerrado-vereda. Revista Brasileira de Botânica 26: 131-140.

DeLucia, E.H., Shenoi, H.D., Naidu, S.L. \& Day, T.A. 1991. Photosynthetic symmetry of sun and shade leaves of different orientations. Oecologia 87: 51-57.

Dickison, W.C. 2000. Integrative Plant Anatomy. Harcourt Academic Press, San Diego.

Fahn, A. \& Cutler, D.F. 1992. Xerophytes. Gebrüder Borntraeger. Berlin.

Feder, N. \& O'Brien, T.P. 1968. Plant microthecnique some principles and new methods. American Journal of Botany 55: 123-142.

Givnish, T.J. 1988. Comparative studies of leaf form: assessing the relative roles of selective pressures and phylogenetic constraints. New Phytologist 106 (suppl.): 131-160.

Gratani, L., Covone, F. \& Larcher, W. 2006. Leaf plasticity in response to light of three evergreen species of the Mediterranean maquis. Trees 20: 549-558.

Hammer, Ø., Harper, D.A.T. \& Ryan, P.D. 2001. PAST: Paleontological Statistics Software Package for Education and Data Analysis. Palaeontologia Electronica 4: 1-9.

IAPAR. 1994. Cartas climáticas do estado do Paraná. Documento 18, Instituto Agronômico do Paraná, Londrina.

Klich, M.R. 2000. Leaf variations in Elaeagnus angustifolia related to environmental heterogeneity. Enviromental and Experimental Botany 44: 171-183.

Kluge, M., Avadhani, P.N. \& Goh, C.J. 1989. Gas exchange and water relations in epiphytic tropical ferns. In: U. Lüttge (ed.). Vascular Plants as Epiphytes. Ecological Studies 76. Spriger-Verlag, Berlin. pp. 87-109.

Labiak, P.H. \& Prado, J. 1998. Pteridófitas epífitas da Reserva Volta Velha, Itapoá, SC, Brasil. Boletim do Instituto de Botânica 1: 1-79.

Luittge, U. 1997. Physiological Ecology of Tropical Plants. Springer, Berlin.

Marques, A.R., Garcia, Q.S., Rezende, J.L.P. \& Fernandes, G.W. 2000. Variations in leaf characteristics of two species of Miconia in the Brazilian cerrado under different light intensities. Tropical Ecology 41: 47-56.

Medri, M.E. \& Lleras, E. 1980. Aspectos da anatomia ecológica de folhas de Hevea brasiliensis Müell. Arg. Acta Amazonica 10: 463-493.

Mott, K.A., Gibson, A.C. \& O'Leary, J.W. 1992. The adaptive significance of amphistomatic leaves. Plant, Cell and Environment 5: 455-460.

Myers, D.A., Jordan, D.N. \& Vogelmann, T.C. 1997. Inclination of sun and shade leaves influences chloroplast light harvesting and utilization. Physiologia Plantarum 99: 395-404. 
Ogura, Y. 1972. Comparative Anatomy of Vegetative Organs of the Pteridophytes. Gebrüder Borntraeger, Berlim.

Parkhurst, D.F. \& Loucks, O.L. 1972. Optimal leaf size in relation to environment. Journal of Ecology 60: 505-537.

Poulson, M.A. \& DeLucia, E.H. 1993. Photosynthesis and structural acclimation to light direction in vertical leaves of Siphium terebinthinaceum. Oecologia 95: 393-400.

Puijalon, S. \& Bornette, G. 2004. Morphological variation of two taxonomically distant plant species along a natural flow velocity gradient. New Phytologist 163: 651-660.

Pyykkö, M. 1979. Morphology and anatomy of leaves from some woody plants in a humid tropical forest of Venezuelan Guayana. Acta Botanica Fennica 112: $1-41$.

Reginato, M. \& Goldenberg, R. 2007. Análise florística, estrutural e fitogeográfica da vegetação em região de transição entre as Florestas Ombrófila Mista e Densa Montana, Piraquara, Paraná, Brasil. Hoehnea 34: 349-364.

Ribas, R.P. \& Miguel, L.A. 2004. Extração e Comercialização de Folhagens Ornamentais da Mata Atlântica: o Caso da Verdes (Rumohra adiantiformis) no RS. Revista de Economia e Sociologia Rural 42: 575-596.

Roças, G., Scarano, F.R. \& Barros, C.F. 2001. Leaf anatomical variation in Alchornea triplinervia (Spreng) Müll. Arg. (Euphorbiaceae) under distinct light and soil water regimes. Botanical Journal of Linnean Society 136: 213-238.
Robinson, J. 1994. Speculations on carbon dioxide starvation, late tertiary evolution of stomatal regulation and floristic modernization. Plant Cell Environment 17: 345-354.

Saldaña,A., Gianoli, E. \& Lusk, C.H. 2005. Ecophysiological responses to light availability in three Blechnum species (Pteridophyta, Blechnaceae) of different ecological breadth. Oecologia 145: 252-257.

Spencer, W. \& Teeri, J. 1994. Acclimation of photosynthetic phenotype to environmental heterogeneity. Ecology 75: 31-314.

Sultan, S. 2000. Phenotypic plasticity for plant development, function and life history. Trends in Plant Science 5: 537-542.

Thompson, W.A., Kriedemann, P.E. \& Craig, I.E. 1992. Photosynthetic response to light and nutrients in suntolerant and shade-tolerant rainforest trees. I. Growth, leaf anatomy and nutrient content. Australian Journal of Plant Physiology 19: 1-18.

Turner, I.M. 1994. A quantitative analysis of leaf form in woody plants from the world's major brodleaved forest types. Journal of Biogeography 21: 413-419.

Webb, L.J. 1959. A physiognomic classification of Australian rain forests. Journal of Ecology 47: 551-570.

Witkowski, E.T.F. \& Lamont B.B. 1991. Leaf specific mass confounds leaf density and thickness. Oecologica 88: 486-493.

Woodhouse, R. \& Nobel, P. 1982. Stipe anatomy, water potentials and xylem conductances in seven species of ferns (Filicopsida). American Journal of Botany 69: 135-142. 